\title{
A METHOD FOR THE DETERMINATION OF D(-)-LACTIC ACID
}

\author{
C. J. A. VAN DEN HAMER* AND R. W. ELIAS \\ Bacteriological Department, Laboratory of Hygiene, University of Utrecht (The Netherlands)
}

\section{INTRODUCTION}

Accounts of several good methods for the determination of the total amount of lactic acid have been published ${ }^{1,2}$. Reliable methods for the separate determination of $\mathrm{D}(-)$ - or $\mathrm{L}(+)$-lactic acid are less plentiful. The usual method is the determination of the water content and the optical rotation of the zinc salt ${ }^{3}$. Furthermore, oxidation with DPN and lactic acid dehydrogenase ${ }^{4,5}$, oxidation with resting cells ${ }^{6}$ and oxidation with cell-free preparations of microorganisms ${ }^{7}$ are often used. A separation of optically active and racemic lactic acid by paper chromatography is also possible ${ }^{8}$. Each of these methods has its own advantages and specific applications. Isolation of zinc lactate, for instance, is time-consuming and only possible with large quantities of lactic acid. The spectrophotometric determination with DPN and lactic acid dehydrogenase - commonly used in hospitals - is very sensitive, but expensive.

The method described here is based on the observation of HAUGAARD ${ }^{9}$ that a cell-free preparation of $E$. coli $\mathrm{B}$, grown in a medium with DL-lactate as the only carbon source, oxidizes both $\mathrm{D}(-)$ - and $\mathrm{L}(+)$-lactate to pyruvate, whereas an acetone powder of this preparation attacks only $\mathrm{D}(-)$-lactate; in the latter case methylene blue has to be added. We observed that an acetone powder of whole cells of $E$. coli $\mathrm{B}$ has the same properties. When a lactic acid-containing sample is incubated with the acetone powder, methylene blue and phosphate buffer in a Warburg apparatus, the oxygen consumption is a measure for the amount of $\mathrm{D}(-)$-lactic acid in the sample. The method was specially useful in the study of bacterial fermentation products.

\section{Preparation of acetone powder}

\section{METHODS AND MATERIALS}

Stock cultures of a strain of $E$. coli B were kept on nutrient agar. In order to prepare the acetone powder the organism was inoculated from stock cultures into a small volume of a liquid medium with DL-lactate as the sole carbon source. This medium was prepared according to

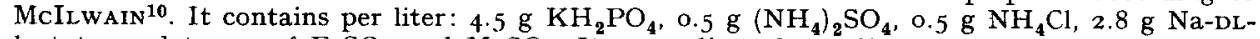
lactate, and traces of $\mathrm{FeSO}_{4}$ and $\mathrm{MgSO}_{4}$. It was adjusted to $\mathrm{pH} 7.6$ with sodium hydroxide, filtered, and sterilized by boiling for some minutes. This culture was shaken or aerated with sterile air at $30^{\circ} \mathrm{C}$ for $24 \mathrm{~h}$ and the whole culture was used as an inoculum for a 15 fold volume of the same medium. In this way larger quantities of cells were obtained. The final culture was again aerated at $30^{\circ} \mathrm{C}$ for 24 hours. When aeration had been sufficient the culture was very turbid, showing $80 \%$ light absorption (white light).

Cells were harvested by centrifugation, washed twice with saline, and suspended in a volume of saline (about $0.25 \%$ of the culture volume). While stirring vigorously and cooling with water of $0^{\circ} \mathrm{C}$ a 5 -fold volume of cold acetone was slowly added. The precipitated cells were resuspended by mechanical stirring in about one volume of cold acetone and centrifuged. This procedure was

\footnotetext{
* This investigation was supported by a grant from the Netherlands Organization for Pure Research (Z.W.O.).
}

References p. $561 / 562$. 
repeated three times, water-free acetone being used for the last treatment. The wet acetone powder was then spread in a thin layer in a Petri dish and dried at room temperature in vacuo. From $\mathrm{I} l$ of medium, $0.5-0.65 \mathrm{~g}$ dry powder was obtained. After storage during one year at $4^{\circ} \mathrm{C}$ or one month at room temperature no reduction in activity was found. Not all strains gave equally satisfactory results.

\section{Standard assay}

In order to determine $\mathbf{D}(-)$-lactic acid in a fermentation supernatant, $35^{\circ} \mathrm{mg}$ acetone powder was suspended into io $\mathrm{ml}$ phosphate buffer $0.2 M, \mathrm{pH} 7.5$, as homogeneously as possible. Elimination of clumps by decantation and filtration over a Willstätter nail without filter paper can produce a more homogeneous suspension.

For the determination, conventional Warburg vessels were used. The centre well contained $0.1 \mathrm{ml} \mathrm{10} \% \mathrm{KOH}$, the sidearm(s) $0.2-0.6 \mathrm{ml}$ sample, and the main compartment $\mathrm{I}$ ml suspension of acetone powder in $M / 5$ phosphate buffer, $\mathrm{pH} 7.5,0.3 \mathrm{ml} 2.5 \%$ methylene blue and water, so that the final volume in the whole flask was $2.4 \mathrm{ml}$. The gas phase was air, the incubation temperature $37^{\circ}$, and the shaking frequency about 70 per minute. The oxygen consumption was compared in the usual manner with that in a vessel without sample ${ }^{11}$.

Fig. I shows a typical experiment. All values were corrected for the value of the vessel without sample. The oxygen consumption was found after the manometer readings had become constant. In those cases where the curve did not become completely horizontal but continued to rise at a low slope the oxygen consumption was found by extrapolation to zero time (Fig. 1).

Total and $\mathrm{L}(+)$-lactic acid

The total amount of lactic acid in the sample was generally determined according to a modification $^{12}$ of the procedure of BARKER AND SUMMERSON ${ }^{2}$. The amount of $L(+)$-lactic acid was found as the difference between total and $\mathbf{D}(-)$-lactic acid.

\section{Lactate preparations used}

In order to test the method the following lactate preparations were used:

(a) $\mathbf{L}(+)$-lactic acid, obtained commercially as the free acid. Before use it was neutralized with $\mathrm{KOH}$,

(b) $\mathrm{D}(-)$-lactic acid, prepared with Lactobacillus leichmannii ATCC 4797 and isolated as the zinc salt, according to BRIN ${ }^{13}$, after it had been extracted from the acidified fermentation medium with ethvl ether ${ }^{14}$. Before use it was converted to the free acid with Dowex- 5 o and neutralized with $\mathrm{KOH}$.

(c) Li-DL-lactate was a gift of the Central Institute for Food Research (Mr. WiLlemse). It was used in the state in which it was received.

\section{RESULTS AND DISCUSSION}

Our acetone powder, prepared from whole cells of $E$. coli B, acted in the presence of methylene blue in the same way as the acetone powder from a cell-free preparation of $E$. coli B described by HAUGAARD ${ }^{9}$ (Fig. I). $0.5 \mu$ mole oxygen was consumed per $\mu$ mole $\mathrm{D}(-)$-lactic acid, whereas $\mathrm{L}(+)$-lactic acid was scarcely affected. After omission of $\mathrm{KOH}$ from the centre well essentially the same manometer readings resulted, so no $\mathrm{CO}_{2}$ was produced. After oxygen consumption was complete, pyruvic acid was found $\mathrm{d}^{15}$ in the vessels in quantities equimolecular with the amount of $\mathrm{D}(-)$-lactic acid added.

\section{Optimal conditions}

As the method appeared satisfactory-and, in fact, after it had been used for some time with good results - we checked whether the conditions of assay were the optimal conditions (Fig. 2-6). In these figures the conditions of assay are indicated by an arrow. It was found that the concentration of methylene blue and of acetone powder were not limiting factors (Fig. 2 and 3). The amount of $\mathrm{D}(-)$-lactic acid in the vessels had no influence on the reaction velocity within a range of $0.25-3.0 \mathrm{mg}$ (Fig. 4). Variation of the buffer concentration from $0.05-0.28 M$ did not influence the results. The $\mathrm{pH}$ optimum was studied in phosphate and glycine-sodium hydroxide 
buffers (Fig. 5). The pH of the buffer (Fig. 5) used in the assay was not quite optimal. As the use of phosphate buffer was more convenient for our purposes and the buffer capacity of phosphates at $\mathrm{pH} 8$ is small we continued to use $\mathrm{pH} 7.5$. The oxygen supply is the limiting factor of the reaction velocity (Fig. 6). An increase of shaking

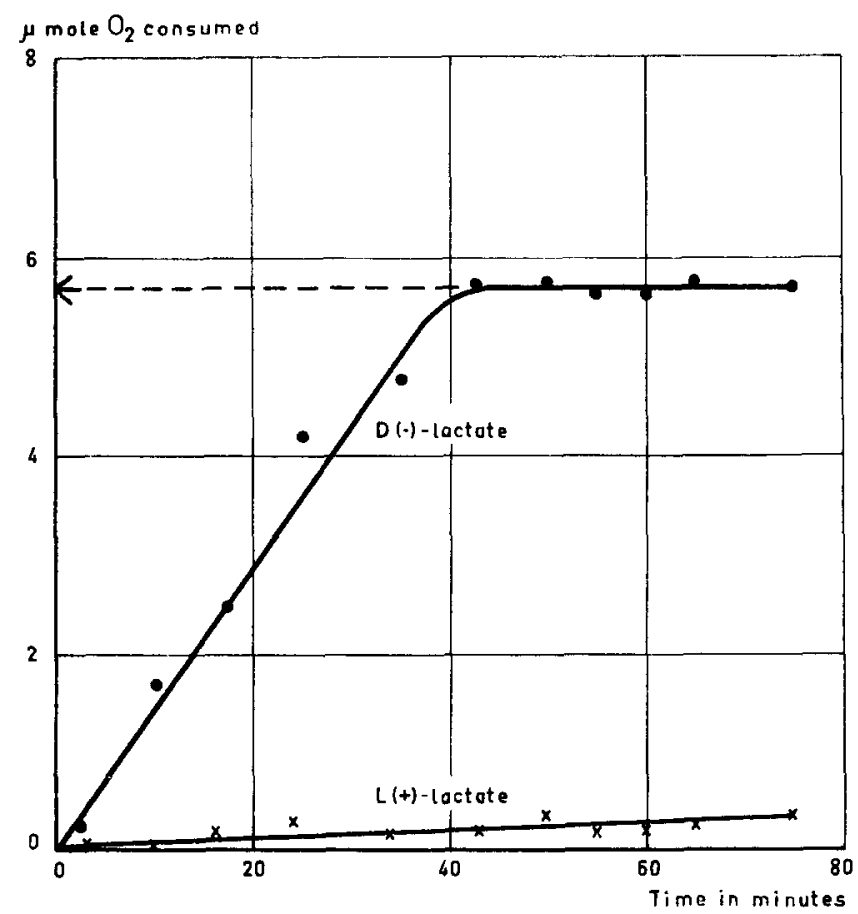

Fig. 1. Determination of $\mathrm{D}(-)$-lactic acid. The Warburg vessels contained $\mathrm{o}$. I $\mathrm{ml} \mathrm{KOH}$ (in the centre wells), $35 \mathrm{mg}$ acetone powder of $E$. coli B suspended in $1 \mathrm{ml} \mathrm{o.2} M$ phosphate buffer, $\mathrm{pH} 7.5,0.3 \mathrm{ml} \mathrm{2.5 \%}$ methylene blue, I I.1 $\mu$ mole substrate as indicated (in the side arm) and water to a final volume of $2.4 \mathrm{ml}$. Other conditions see text.

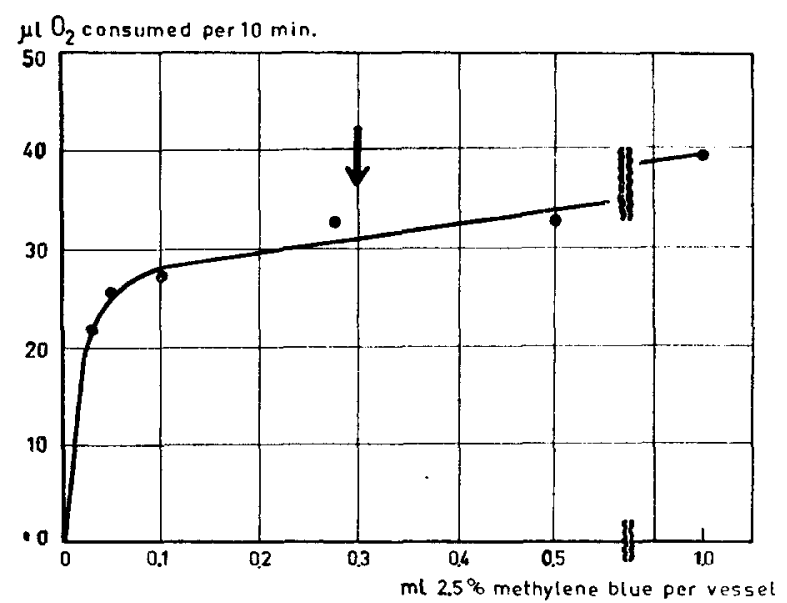

Fig. 2. Effect of the methylene blue concentration on the rate of oxidation. Conditions are as described in Fig. I. The arrow indicates the amount of methylene blue as used in our standard assay. Note discontinuation in the scale. 
frequency of the Warburg vessels from 40 to about 90 per minute augmented the reaction rate 2.4 times. The substitution of the air in the gas phase by pure oxygen augmented the reaction velocity 2.0 times at the low frequency and 2.6 times at the higher frequency of shaking.

Fig. 2-6 show that the chosen conditions are nearly optimal. The reaction rate

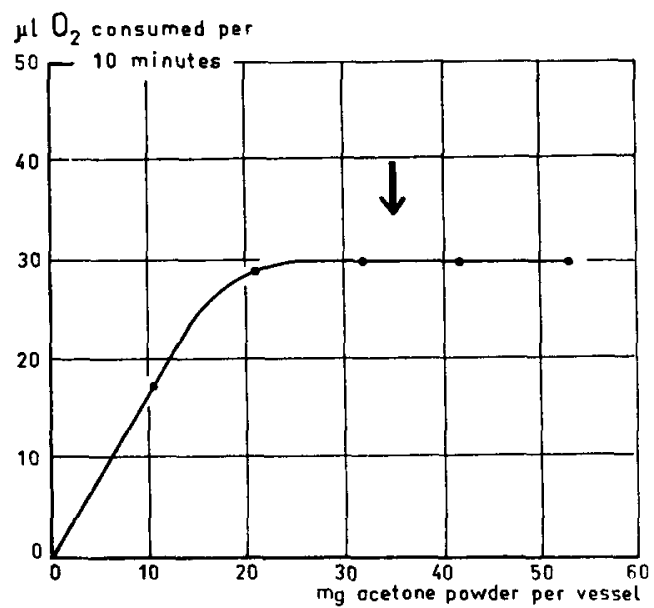

Fig. 3. Effect of the amount of acetone powder on the rate of oxidation. Conditions are as described in Fig. $\mathrm{x}$. The arrow indicates the amount of acetone powder as used in our standard assay.

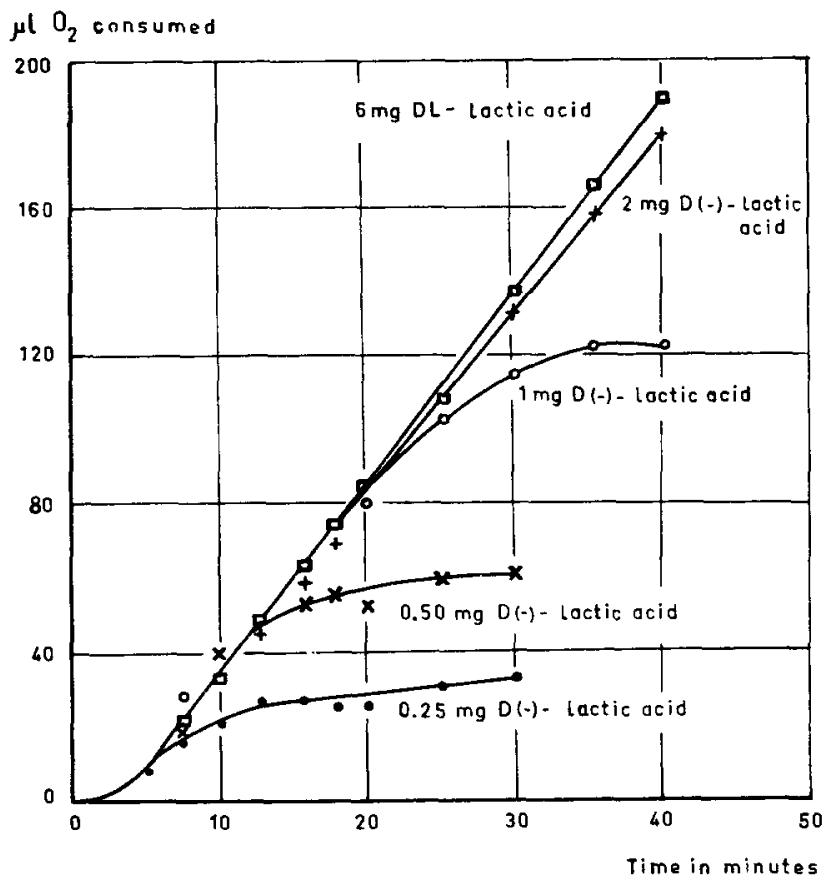

Fig. 4. Effect of the substrate concentration on the rate of oxidation. Substrates as indicated. Other conditions are as described in Fig. 1.

References p. $561 / 5^{62}$. 
could be increased by a higher $\mathrm{pH}$ or by increased oxygen supply. As the determination of $\mathrm{D}(-)$-lactic acid did not depend on the reaction rate but on the total amount of oxygen consumed, we continued to use the original conditions.

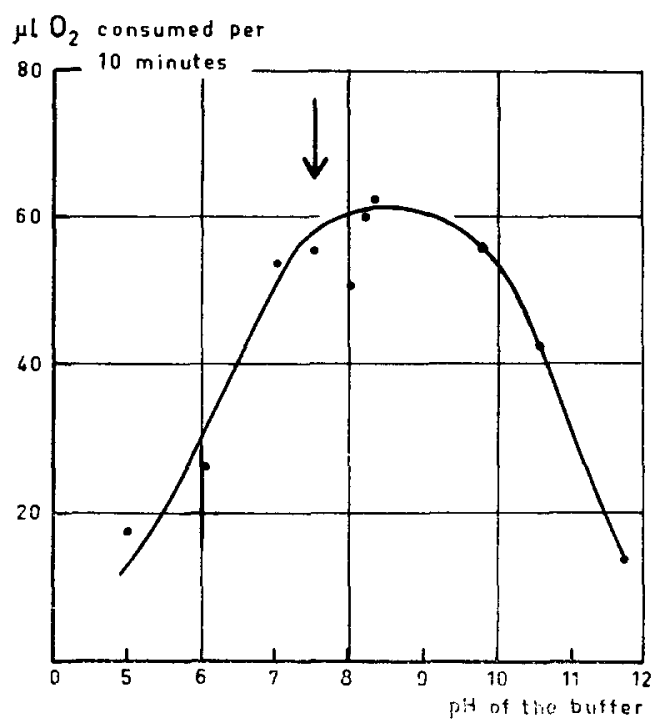

Fig. 5. Effect of the $\mathrm{pH}$ on the rate of oxidation. Conditions are as described in Fig. 1 . The arrow indicates the $\mathrm{pH}$ of our standard assay.

\section{Specificity}

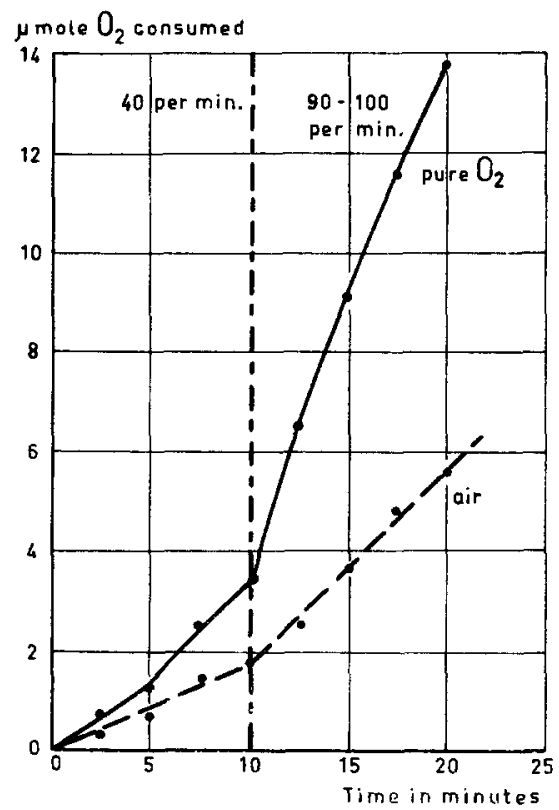

Fig. 6. Effect of oxygen on the rate of oxidation. After 10 minutes the shaking frequency is increased from 40 per minute to $90-100$ per minute. Solid line indicates pure oxygen as gas phase. Substrate was 66.7 /mole Li-DL-lactate.

Other conditions are as described in Fig. I.

For a number of compounds other than lactic acid we estimated the oxidation by the acetone-powder under the conditions of our assay. Especially those compounds were tested that might be present as substrate or product in fermentation fluids of lactic acid bacteria. Table I gives some of these results. The rate of oxygen consumption rather than total oxygen consumption is given here, since another substance broken

TABLE I

OXIDATION RATES OF VARIOUS SUBSTANCES

\begin{tabular}{|c|c|c|}
\hline amoles & Compound & atl $\mathrm{O}_{2}$ in $10 \mathrm{~min}$ \\
\hline 20 & $\mathrm{~K}-\mathrm{D}(-\rightarrow)$-lactate & $30-32$ \\
\hline 20 & I i-DL-lactate & $30-32$ \\
\hline I I . I & $\mathbf{L}(+)$-lactate & $\mathrm{I}$ \\
\hline 20 & $\mathrm{~K}-\mathrm{D}(-)$-lactate $+20 \mu$ mole $\mathrm{As}_{2} \mathrm{O}_{3}$ & $30-32$ \\
\hline I $3 \cdot 3$ & Arabinose & o \\
\hline I I. 2 & Gluconolactone & I \\
\hline II.I & Glucose & o \\
\hline I $3 \cdot 3$ & Ribose & $\mathrm{O}$ \\
\hline $13 \cdot 3$ & Xylose & 0 \\
\hline
\end{tabular}

References p. $561 / 562$. 
down at a very low rate would not affect specificity very much. It should be remembered that under our conditions the rate is not optimal. To date no substance has been found which was oxidized at an appreciable rate. A possible decarboxylation of some substances has not been excluded since in all cases the centre well contained $\mathrm{KOH}$. With pure lactic acid preparations the $\mathrm{KOH}$ can be omitted.

Within the limits of experimental accuracy no oxygen consumption was obtained with the following substances: acetate, acetylmethylcarbinol, K-citrate, ethanol, glycerol, glycine, glycylglycine, K-DL-malate, K-oxalacetate, K-propionate and Napyruvate.

\section{Sensitivity}

The sensitivity depends mainly on the shape of the bend of the curve (Fig. I), i.e., in fact, on the velocity of the reaction. Under our conditions $0.1-0.2 \mathrm{mg}$ lactic acid had to be present for reasonable accuracy. The limiting factor is the scattering of the manometer readings in the horizontal part of the curve, which determine the total oxygen consumption.

Accuracy was not studied in detail. In Io observations derived from three series of experiments with Io $\mu$ moles D(-)-lactate th $\epsilon$ quantities of oxygen consumed varied from 9.73 to Io.I $\mu$ atoms of oxygen. The mean was $9.92 \mu$ atoms and the standard error of each observation was $0.182 \mu$ atoms. With smaller amounts of lactic acid the error would be larger. Under our conditions, with amounts of lactic acid in the region of $0 . \mathrm{I}-2 \mathrm{mg}$ lactic acid the error of a single experiment would be in the order of $5-10 \%$.

The described method permits the estimation of $\mathrm{D}(-)$-lactic acid in a number of samples (depending on the apparatus) in a rather short time. The method requires a Warburg apparatus. Attempts to use Thunberg technique showed less accurate results.

\section{ACKNOWLEDGEMENT}

We are very grateful to Professor Dr. K. C. WINkLER for his constant interest and to Mr. K. C. STRAsteks for preparing D(-)-lactic acid and carrying out some preliminary experiments.

\section{SUMMARY}

A method for the determination of $\mathrm{D}(-)$-lactic acid is described. An acetone powder from Escherichia coli $\mathrm{B}$ in the presence of methylene blue oxidizes $\mathrm{D}(-)$-lactic specifically. Oxygen consumption in a Warburg apparatus was used as a measure of the $\mathrm{D}(-)$-lactic acid.

\section{REFERENCES}

1 T. E. Friedemann and J. B. Graeser, J. Biol. Chem., ioo (I933) 29 I.

2 J. B. Barker and W. H. Summerson, $j$. Biol. Chem., I 38 (194I) 535.

3 C. S. Pederson, W. H. Peterson and E. B. Fred, J. Biol. Chem., 68 (1926) I 5 I.

4 G. Pfleiderer and K. Dose, Biochem. $Z$., 326 (I955) 436.

5 H. D. Horn and F. H. Bruns, Biochim. Biophys. Acta, 2 I (I956) 378.

${ }^{6} \mathrm{~K}$. Kitahara and S. Fukui, Symposia on Enzyme Chem., 8 (1953) 1o8.

7 J. G. Dewan and D. E. Green, Biochem. $J$., $3^{\text {I }}$ (1937) 1074.

${ }^{3}$ H. Katagiri, K. Imai and T. SUgimori, Symposia on Enzyme Chem., ro (1954) 203. 
9 N. HaugaARd, Federation Proc., 9 (I950) I 82.

${ }^{10}$ H. MCIlwaIN, Biochem. J., 35 (I94I) I 3I I.

11 W. W. Umbreit, R. H. Burris and J. F. Stauffer, Manometric techniques, 2nd ed., Burgess Publ. Co., Minneapolis, 1949.

12 A. C. NeIsh, Analytical Methods for Bacteriol. Fermentation, 2nd rev. ed., I952.

13 M. Brin, Biochem. Prep., 3 (1953) 61.

14 M. Brin, R. E. Olsen and F. J. Stare, Arch. Biochem. Biophys., 39 (I952) 2 I 4

15 Th. E. Friedemann and G. E. Haugen. J. Biol. Chem., 147 (I943) 4 I 5.

Received March 6th, I958

\title{
QUANTITATIVE AMINO ACID ANALYSIS OF FOOD PROTEINS BY MEANS OF A SINGLE ION-EXCHANGE COLUMN
}

\author{
D. S. BIDMEAD AND F. J. LEY \\ Unilever Ltd., Food Research Department, Sharnbrook, Bedfordshive (Great Britain)
}

The Moore And STEIn technique of ion-exchange chromatography for quantitative separation and determination of the individual amino acids in a mixture has been widely used in one or other of its modifications, and has been applied to the analysis of food-protein hydrolysates by SCHRAM et al. ${ }^{1}$. They discussed the precautions to be taken in the acid hydrolysis of proteins in different materials especially those with a high carbohydrate content, and referred particularly to the difficulty of accurately determining cystine and methionine in an acid hydrolysate. Cystine and tryptophan were destroyed to a large extent during the hydrolysis so that separate determinations were required for these amino acids. Methionine also was partially oxidized, forming isomeric sulphoxides which appeared as two small peaks in the chromatogram, and where the methionine content of a particular sample was low, the amount present had to be calculated from the summation of three very small peaks; consequently estimations were often inaccurate.

Schram, Moore and Bigwood ${ }^{2}$ devised a method for the separate determination of the cystine content of a protein by oxidizing the protein material with performic acid prior to hydrolysis. This converted the cystine residues to cysteic acid which was stable to acid hydrolysis. The hydrolysate was then chromatographed on Dowex-2 in the chloro-acetate form, the cysteic acid being eluted as a separate peak following all the other amino acids. PARTRIDGE AND Davis ${ }^{3}$ also used performic acid for the oxidation of cystine but carried out the chromatography on Dowex-50. This gave quicker results, as the cysteic acid appeared in the first few fractions. The same reagent was used by us to convert methionine quantitatively to the sulphone which was also stable to acid hydrolysis, and the technique was modified to permit simultaneous determination of cystine as cysteic acid and methionine as methionine sulphone. Thus, two separate analyses were required on each sample, one on the oxidized material for cystine and methionine, and one on the unoxidized material for all the other amino acids. 